\title{
Conservadorismo e extrema-direita na Europa e no Brasil*
}

\section{Conservatism and far-right forces in Europe and Brazil}

\author{
Michael Löwy \\ Diretor de Pesquisas emérito do Centre National de la Recherche Scientifique (CNRS)/Paris. \\ michael.lowy1@gmail.com
}

\begin{abstract}
Resumo: Temos assistido, na Europa dos últimos anos, a um espetacular ascenso político e eleitoral de forças de extrema-direita, racistas, xenófobas, fascistas ou semifascistas. Um fenômeno que não pode ser unicamente explicado pela crise econômica, já que em dois dos países mais atingidos por ela, Portugal e Espanha, a extrema-direita é pouco presente no cenário político, enquanto tem um papel muito significativo em países que pouco sofreram com essa crise (Suíça, Áustria). No Brasil não temos partidos racistas, a extrema-direita se manifesta no chamado a um golpe militar.
\end{abstract}

Palavras-chave: Extrema-direita. Fascismo. Racismo. Golpismo.
Abstract: Lately in Europe, we have seen a spectacular political and electoral increase of the far-right forces, which are racist, xenophobic, fascist or semi-fascist. Such a phenomenon cannot be explained solely by the economic crisis, since in two of the most affected countries - Portugal and Spain - the far-right force's presence is little in the political scene, while it has a very significant role in countries which did not suffer a lot because of such a crisis (Switzerland, Austria). In Brazil we do not have racist parties, the far-right force manifests itself in the calling of a military coup.

Keywords: Far-right. Fascism. Racism. Coup.

\section{A extrema-direita na Europa}

seleições europeias na França confirmaram uma tendência que, há
alguns anos, já estava aparente: o crescimento do apoio à Frente
Nacional. Essa evolução não é especificamente francesa: por qua-

* Tradução de Deni Alfaro Rubbo e Marcelo Netto Rodrigues. 
O fenômeno não encontra precedentes desde os anos 1930. Em muitos países, a direita xenófoba já havia obtido entre 10\% e 20\% dos votos durante a última década; em 2014, em três países (Reino Unido, Dinamarca, França) alcançaram de $25 \%$ a $30 \%$. Além disso, sua influência é maior do que o seu próprio eleitorado: suas ideias contaminam também a direita “clássica" e até parte da esquerda social neoliberal. O caso francês é o mais sério deles, com o avanço da Frente Nacional excedendo até mesmo as previsões mais pessimistas. Como escreveu em um editorial recente o site Mediapart, "são cinco minutos para meia-noite".

Pode essa situação ser comparada à Europa dos anos 1930? Sim e não. É a primeira vez, desde os anos 1930, que a extrema-direita alcança tal influência na política europeia. Mas a história nunca se repete. Há muitas diferenças entre as conjunturas do passado e as do presente. A mais óbvia é que, depois de 1933, dois dos mais importantes países da Europa, Itália e Alemanha, tiveram regimes fascistas totalitários. Afortunadamente, nada comparável existe hoje! Uma outra diferença importante é que os interesses da burguesia hoje são esmagadoramente favoráveis à globalização capitalista neoliberal e hostis ao nacionalismo econômico - um conteúdo básico de qualquer projeto fascista ou semifascista. Por outro lado, a esquerda antifascista, tanto em sua versão mais radical - marxistas e anarquistas - quanto em sua forma mais moderada, parlamentar, da Frente Popular, era muito mais forte nos anos 1930 do que hoje. Outra diferença é que, paradoxalmente, ao contrário da época atual, a maioria dos movimentos fascistas dos anos 1930, com a notável exceção da Alemanha (e, em uma escala muito menor, França), não era abertamente racista. Isso se aplica, ao menos até antes de 1938, aos movimentos liderados por Mussolini, Franco e Salazar na Itália, Espanha e Portugal.

A atual extrema-direita europeia é muito diversa, uma variedade que vai de partidos abertamente neonazistas, como o Aurora Dourada na Grécia, a forças burguesas perfeitamente bem integradas ao jogo político institucional, como o suíço UDC. O que eles têm em comum é o seu nacionalismo chauvinista - e, portanto, oposição à globalização "cosmopolita" e a qualquer forma de unidade europeia — , xenofobia, racismo, ódio a imigrantes e ciganos 
(o povo mais antigo do continente), islamofobia e anticomunismo. Além disso, em sua maioria, se não em sua totalidade, são favoráveis a medidas autoritárias contra a "insegurança" (usualmente associada a imigrantes) por meio do aumento da repressão policial, penas de prisão e pela reintrodução da pena de morte. A orientação reacionária nacionalista, na maioria das vezes, é "complementada" com uma retórica "social”, em apoio às pessoas simples e à classe trabalhadora (branca) nacional. Em outras questões - por exemplo, neoliberalismo, democracia parlamentar, antissemitismo, homofobia, misoginia ou secularismo - esses movimentos são mais divididos.

Muitos "especialistas" e comentaristas de mídia anunciam que fascismo e antifascismo são fenômenos pertencentes ao passado. Acreditamos que a realidade é um tanto mais complexa. É óbvio que hoje não vemos partidos fascistas de massa comparáveis ao NSDAP na Alemanha dos anos 1930, mas já naquele período o fascismo não se limitava apenas a esse modelo: o franquismo espanhol e o salazarismo português eram muito diferentes dos modelos italiano e alemão. Até mesmo partidos que tentaram imitar o exemplo alemão, como o Partido Popular Francês (PPF) fundado por Jacques Doriot em 1936 - uma organização claramente fascista que viria a se tornar uma das principais forças colaboracionistas durante o regime de Vichy dificilmente podem ser comparados ao NSDAP alemão. Seria, portanto, um erro alegar que não existem partidos fascistas atualmente na Europa, por não termos nada equivalente aos nacional-socialistas dos anos 1930.

Uma tentativa de tipologia da extrema-direita europeia atual teria de distinguir pelo menos três tipos diferentes:

I. Partidos de caráter diretamente fascista e/ou neonazista: por exemplo, o Aurora Dourada, da Grécia; o Jobbik, da Hungria; o Setor Direito, da Ucrânia; o Partido Nacional Democrata, na Alemanha; e várias outras forças menores e menos influentes. Aqui também se incluiria a recente criação atípica francesa "nacional-socialista" e antissemita Reconciliação Nacional (Alain Soral).

II. Partidos semifascistas, isto é, com raízes e fortes componentes fascistas, mas que não podem ser identificados com o padrão fascista clássico. 
É o caso, em diferentes formas, da Frente Nacional, da França; do FPÖ, da Áustria; e do Vlaams Belang, da Bélgica, entre outros. Seus líderes fundadores tinham ligações estreitas com o fascismo histórico e com as forças que colaboraram com o Terceiro Reich, e vários de seus quadros não escondem a nostalgia pelo passado fascista. Mas suas lideranças atuais tentam "modernizá-los", apresentando uma imagem mais "respeitável", por exemplo, substituindo antissemitismo por islamofobia. Por razões que explicaremos adiante, consideramos o conceito de "populismo" como totalmente inadequado para caracterizar esses partidos.

III. Partidos de extrema-direita que não possuem origens fascistas mas compartilham do seu racismo, xenofobia, retórica anti-imigrante e islamofobia. Exemplos são a italiana Lega Nord, o suíço UDC (União Democrática do Centro), o britânico Ukip (Partido de Independência do Reino Unido), o holandês Partido da Liberdade, o norueguês Partido Progressista, o Partido dos Verdadeiros Finlandeses (True Finns) e o Partido do Povo Dinamarquês. Os Democratas Suecos são um caso intermediário, com origens claramente fascistas (e neonazistas), mas que têm feito grandes esforços, desde os anos 1990, para apresentar uma imagem mais "moderada".

Como em todas as tipologias, a realidade é mais complexa, e algumas dessas formações políticas parecem tomar parte de vários tipos diferentes. É preciso também levar em conta que isso não é uma estrutura estática, mas sim em constante movimento. Alguns desses partidos parecem mover de um tipo a outro. No momento, há somente um exemplo na Europa de um partido fascista tornando-se um partido de direita "normal": o italiano Aliança Nacional, de [Gianfranco] Fini. Não se pode excluir a possibilidade que outros partidos similares sigam esse caminho, mas, por ora, não existem sinais de tal desenvolvimento.

Embora as ideologias dos partidos de extrema-direita possuam muitas similaridades, sua prática política não é homogênea. Enquanto alguns, como o francês FN, pretendem ser "antissistêmicos" e permanecem, por ora, fora das instituições de poder, outros, como o Partido da Liberdade da Áustria e o italiano Lega Nord têm, em anos recentes, participado de governos; os 
partidos dinamarquês e holandês apoiaram seus governos sem se unir a eles, enquanto o suíço UDC e o norueguês Partido Progressista no momento fazem parte de coalizões governamentais.

A extrema-direita na Europa Oriental — as antigas "Democracias Populares" - como o partido húngaro Jobbik, o Partido da Grande Romênia e o Atak, da Bulgária, assim como partidos similares nas Repúblicas Balcânicas, Ucrânia, ex-Iugoslávia etc., têm algumas características comuns que são, em certa medida, distintas dos seus equivalentes no Ocidente: a) o bode expiatório é menos o imigrante estrangeiro do que as minorias nacionais tradicionais: judeus e ciganos; b) diretamente conectado a esses partidos ou tolerado por eles, gangues racistas violentas atacam, e algumas vezes matam, o povo Roma [cigano]; c) raivosamente anticomunistas, eles se consideram herdeiros dos movimentos nacionalista e/ou fascista dos anos 1930, que frequentemente colaboraram com o Terceiro Reich. $\mathrm{O}$ fracasso desastroso da assim chamada "transição" (para o capitalismo), sob a liderança de partidos liberais e/ou social-democratas, criaram condições favoráveis para o surgimento de tendências de extrema-direita. ${ }^{1}$

Qualquer que seja a sua transformação e "modernização", a extrema-direita ainda representa uma ameça real à democracia. Um dos argumentos usados para mostrar que ela mudou e não tem muito mais a ver com o fascismo é a aceitação da democracia parlamentar e da via eleitoral para chegar ao poder. Bom, podemos lembrar que certo Adolf Hitler chegou a chanceler alemão por voto legal no Reichstag e que o marechal Pétain foi eleito chefe de Estado pelo Parlamento francês. Se a Frente Nacional chegasse ao poder por meios eleitorais - uma hipótese que tristemente não pode mais ser descartada - o que sobraria de democracia na França?

Como explicar esse sucesso crescente da extrema-direita? O primeiro elemento de explicação é o processo de globalização capitalista neoliberal — também um poderoso processo de homogeneização cultural forçada que produz e reproduz, em escala europeia e planetária, os identity panics

1. Ver Dominique Vidal, Le ventre est encore fecond. Les nouvelles extrêmes droites européennes. Paris: Libertalia, 2012. p. 129-148. 
[pânicos de identidade], a obsessiva procura por fontes e raízes que leva a formas chauvinistas de religião, formas religiosas de nacionalismo, além de alimentar conflitos étnicos e confessionais. ${ }^{2}$

Diretamente relacionado a esse processo de hegemonia mundial neoliberal do capital financeiro há um outro fator importante: a crise econômica que tem despedaçado a Europa desde 2008. Exceto na Grécia e na Espanha, essa crise tem em quase todos os lugares favorecido muito mais a extrema-direita do que a esquerda radical — diferente da situação europeia dos anos 1930, quando em muitos países a esquerda antifascista cresceu paralelamente ao fascismo. A extrema-direita atual tem, sem dúvida, se beneficiado da crise, particularmente na França. Mas isso não explica tudo: na Espanha e em Portugal, dois dos países mais atingidos duramente pela crise, a extrema-direita permanece apenas marginal. E na Grécia, apesar de a Aurora Dourada ter desfrutado de um crescimento exponencial, ela possui muito menos influência do que o Syriza, a coalizão da esquerda radical. Na Suíça e na Áustria, dois países em grande parte poupados pela crise, a extrema-direita racista muitas vezes fica acima de $20 \%$ de apoio. Portanto, devemos evitar as explicações exclusivamente economicistas muitas vezes apresentadas pela esquerda.

Fatores históricos têm, sem dúvida, jogado algum papel: uma longa tradição antissemita espalhada em certos países; a persistência daquelas correntes que colaboraram durante a Segunda Guerra Mundial; e a cultura colonial que impregna atitudes e comportamentos mesmo muito tempo depois da descolonização - não só nos antigos impérios, mas em quase todos os países europeus. Todos esses fatores estão muito presentes na França e contribuem para explicar a força do partido de Le Pen, mas são menos relevantes em países sem um passado colonial ou fascista, como a Suíça.

A conjuntura internacional, particularmente no Oriente Médio, também favorece esse cenário. As agressivas políticas coloniais e expansivas do governo israelense nutrem antissemitismo (particularmente entre os jovens

2. Daniel Bensaïd, Fragments mécréants. Mythes identitaires et République imaginaire. Paris: Lignes, 2005, passim. 
muçulmanos) mal disfarçado como "antissionismo", ao passo que o terror do Estado islâmico (Daesh) e de outros jihadistas assassinos alimenta a islamofobia, pretensamente em nome do "secularismo". É lógico que não é por causa de Netanyahu ou Bin Laden que o racismo e a xenofobia se desenvolveram na Europa, mas os eventos negativos no Oriente Médio são habilmente manipulados pela extrema-direita para promover sua agenda, com considerável sucesso. $\mathrm{O}$ mesmo se aplica, logicamente, aos ataques terroristas na Europa - como os assassinatos recentes dos editores do jornal satírico Charlie Hebdo - que são usados como munição pela direita racista para empreender a sua "guerra de civilização" contra os cidadãos muçulmanos europeus.

A esquerda como um todo, com apenas algumas exceções, tem severamente subestimado esse perigo. Não viu a "onda marrom” vindo e, portanto, não viu a necessidade de tomar a iniciativa de uma mobilização antifascista. Para algumas correntes da esquerda que veem a extrema-direita como nada mais do que um efeito colateral da crise e do desemprego, são essas as causas que devem ser atacadas, e não o fenômeno fascista propriamente dito. Tal raciocínio tipicamente economicista desarmou a esquerda diante da ofensiva ideológica racista, xenofóbica e nacionalista da extrema-direita.

Nenhum grupo social é imune à praga marrom. As ideias da extrema-direita, em particular o racismo, contaminaram uma parte significativa não só da pequena burguesia e dos desempregados, mas também da classe trabalhadora e da juventude. Isto é particularmente notável no caso francês. Essas ideias não têm relação nenhuma com a realidade da imigração: o voto para a Frente Nacional, por exemplo, foi particularmente alto em certas áreas rurais que nunca viram um único imigrante. E os imigrantes ciganos [Roma], recentemente objeto de uma campanha racista histérica que deixou algumas impressões - com a participação generosa do ministro do Interior "socialista" da época, o sr. Manuel Valls — chegam a menos do que $20 \mathrm{mil}$ em toda a França.

A análise "clássica" de esquerda sobre o fascismo o explica essencialmente como um instrumento do grande capital para esmagar a revolução e o movimento dos trabalhadores. Com base nessa premissa, algumas pessoas 
da esquerda argumentam que já que hoje o movimento dos trabalhadores está muito enfraquecido e a ameaça revolucionária não existe, o grande capital não teria interesse em apoiar movimentos da extrema-direita, de modo que o risco de uma ofensiva marrom não existiria. Esta é, uma vez mais, uma leitura economicista que não leva em conta a autonomia de nenhum fenômeno político. Os eleitores podem, na verdade, escolher um partido que não tem o apoio da grande burguesia. Além disso, esse estreito argumento econômico parece ignorar o fato de que o grande capital pode acomodar-se em todos os tipos de regimes políticos sem muito exame de consciência.

O conceito de "populismo" empregado por certos cientistas políticos, mídia e até mesmo por parte da esquerda é totalmente inadequado para explicar a natureza da Frente Nacional (ou seus equivalentes na Europa), servindo apenas para semear confusão. Na América Latina dos anos 1930 até os anos 1960, o termo populismo correspondia a algo bem específico: governos nacionais populares ou movimentos ao redor de figuras carismáticas - Vargas, Perón, Cárdenas — , com amplo apoio popular e uma retórica anti-imperialista. Entretanto, o seu uso francês (ou europeu) a partir dos anos 1990 é terrivelmente vago e impreciso. Um dos primeiros a usar o termo para caracterizar o movimento de Le Pen foi o cientista político P.-A. Taguieff, que definiu populismo como "um estilo retórico que está diretamente ligado com o apelo ao povo". ${ }^{3}$ Outros cientistas sociais se referem ao populismo como "uma posição política que toma o lado do povo contra as elites" - uma caracterização que serve para quase todo partido político ou movimento! Quando aplicado à Frente Nacional ou outros partidos europeus da extrema-direita, esse pseudoconceito transforma-se em um eufemismo enganoso que ajuda — seja deliberadamente ou não — a legitimá-los, tornando-os mais aceitáveis ou mesmo atraentes - quem não é a favor do povo contra as elites? - enquanto cuidadosamente se evitam os termos perturbadores racismo, xenofobia, fascismo ou extrema-direita. "Populismo"

3. P.-A. Taguieff, Le populisme et la science politique, Vingtième siècle, 1997. p. 8.

4. Ver o interessante livro de Annie Collovald. Le "populisme du FN", un dangereux contresens. Broissieux: Editions du Croquant, 2004. p. 53 e 113. (Col. Raisons d'agir.) 
também é usado deliberadamente de uma forma mistificadora por ideologias neoliberais e pela mídia na França (assim como na Europa), a fim de fazer um amálgama entre a extrema-direita, por exemplo, a Frente Nacional, e a esquerda radical, por exemplo a Frente de Esquerda, caracterizadas como "populismo de direita" e "populismo de esquerda", já que ambas se opõem a políticas neoliberais, "Europa" etc.

Jean-Yves Camus, respeitado cientista político francês, explicava que partidos como a Frente Nacional poderiam ser chamados de "populistas" enquanto eles "fingem substituir a democracia representante pela democracia direta" e opõem o "senso comum popular" contra as "elites naturalmente pervertidas". Esse é um argumento muito equivocado, já que o apelo à democracia direta, a crítica da representação parlamentar e das elites políticas é muito mais presente entre os anarquistas e outras correntes políticas de extrema-esquerda do que entre a extrema-direita, cujo projeto político enfatiza o autoritarismo. Felizmente, Camus, que é um dos melhores especialistas da extrema-direita francesa e europeia, recentemente corrigiu seu ponto de vista, argumentando, em 2014, que se deve evitar o emprego do termo "populismo", que tem sido usado "a fim de desacreditar qualquer crítica do consenso ideológico neoliberal, qualquer questionamento sobre a bipolarização do debate político europeu entre os liberais conservadores, qualquer expressão nas urnas do sentimento popular de desafio do mau funcionamento da democracia representativa". ${ }^{5}$

A utilização por parte de alguns pesquisadores do termo "pós-fascismo" para designar a extrema-direita europeia - notadamente a Frente Nacional — parece questionável para nós. O prefixo "pós" — por exemplo, "pós-modernismo" — tem dois significados comuns: a passagem de uma época histórica e a ruptura com um modo de pensar.

No caso da Frente Nacional, "pós-fascismo" refere-se, implícita ou explicitamente, a duas hipóteses que nos parecem errôneas:

5. Jean-Yves Camus. Extrêmes droites mutantes en Europe. Le Monde Diplomatique, p. 18-19, mar. 2014. 
1) O fascismo é uma época histórica ultrapassada, a FN se situa em um período posterior. É o que afirma, por exemplo, um pesquisador como Philippe Milet (cujos trabalhos são geralmente interessantes) de forma explícita: "O FN vem depois do fascismo, seu reformismo é pós-fascista - ele é segundo o fascismo". ${ }^{6}$ No entanto, acreditamos que o fascismo não é (foi) uma época, mas um modo de organização e uma ideologia política que se manifestou, por diferentes formas e por diferentes momentos, bem depois do fim do Terceiro Reich.

2) O FN, por suas ideias e suas práticas, teria operado uma ruptura com o fascismo. Essa parece ser uma hipótese bastante arriscada, que não leva em conta os elementos muito importantes de continuidade entre o lepenismo e sua matriz fascista (petanismo).

Não há nenhuma receita mágica para combater a extrema-direita. Devemos nos inspirar - com uma distância crítica apropriada — nas tradições antifascistas do passado, mas também devemos saber como inovar, a fim de responder às novas formas desse fenômeno. Devemos saber como combinar iniciativas locais com os movimentos culturais e sociopolíticos unitários solidamente organizados e estruturados, tanto em nível nacional quanto em nível continental. Às vezes é possível unir-se com o fantasma do "republicanismo", mas qualquer movimento antifascista só será eficaz e crível se for motivado por forças situadas fora do consenso neoliberal dominante. Isso significa uma luta que não pode ser limitada dentro das fronteiras de um único país, mas deve ser organizada em termos de Europa como um todo. A luta contra o racismo, bem como a solidariedade com as suas vítimas, é um dos componentes essenciais dessa resistência. Ainda não é tarde demais para impedir "a resistível ascensão de Arturo Ui” (para citar a conhecida peça de teatro antifascista por Bertolt Brecht).

6. J. P. Milet. L'extrême droite pour tous. Lignes, p. 55; grifos do autor. 


\section{Conservadorismo e extrema-direita no Brasil}

Não vou me estender sobre o conservadorismo e a extrema-direita no Brasil porque as colegas que falarão depois de mim o farão, com muito mais competência do que eu. Limitar-me-ei a algumas sugestões comparando os fenômenos europeus com o Brasil.

1) Enquanto na Europa existe, em vários países, uma continuidade política e ideológica entre movimentos neofascistas atuais e o fascismo clássico dos anos 1930, isso não ocorre no Brasil. O fascismo brasileiro, o integralismo, chegou a ter bastante peso nos anos 1930, inclusive influenciando o golpe do Estado Novo, em 1938. Mas a extrema-direita brasileira atual tem pouca relação com essa matriz antiga; grupos neofascistas existem, porém são marginais. Nada comparável com a Aurora Dourada grega ou a Frente Nacional francesa.

2) Não existem no Brasil, como no Europa, partidos de massa tendo o racismo como sua principal bandeira. Claro, o Brasil está longe de ser uma democracia racial, e um racismo difuso está bastante presente na sociedade. Porém, um partido brasileiro que tentasse fazer do racismo seu programa principal nunca teria $25 \%$ dos votos como na França...

3) O tema da luta contra a corrupção não é específico da extrema-direita, mas tem sido demagogicamente manipulado, com certo sucesso, por setores conservadores, na Europa e, sobretudo, no Brasil. No Brasil é uma velha tradição, desde os anos 1940, dos conservadores: levanta-se a bandeira do combate à corrupção para justificar o poder das oligarquias tradicionais e, segundo o caso, legitimar golpes militares.

4) O que é comparável na extrema-direita francesa e brasileira são dois temas de agitação sociocultural do conservadorismo mais reacionário:

I. A ideologia repressiva, o culto da violência policial, o chamado a restabelecer a pena de morte: é o caso na Europa da extrema- 
-direita e no Brasil da "bancada da bala", fortemente representada no Congresso.

II. A intolerância com as minorias sexuais, em particular os homossexuais. É um tema agitado, com certo sucesso, por setores religiosos, com referência católica (Opus Dei, Civitas etc.) na França e evangélica neopentecostal no Brasil.

5) O elemento mais preocupante da extrema-direita conservadora no Brasil, que não tem um equivalente direto na Europa, é o apelo aos militares. O chamado a uma intervenção militar, o saudosismo da ditadura militar, é sem dúvida o aspecto mais sinistro e perigoso da recente agitação de rua conservadora no Brasil, ativamente promovido pelo PIG, o Partido da Imprensa Golpista.

Certo, já não estamos no período da Guerra Fria, em que se sucederam os golpes militares na América Latina, patrocinados pelo imperialismo americano. Mas não podemos esquecer que houve tentativas golpistas na Venezuela, na Bolívia e no Equador. Pior do que isso: muito recentemente, golpes de Estado pseudolegais, com cobertura parlamentar, tiveram lugar, com sucesso, em Honduras e no Paraguai.

Gostaria de concluir propondo uma pista de reflexão: o sistema capitalista, sobretudo nos períodos de crise, produz e reproduz fenômenos como o fascismo, o racismo, os golpes de Estado e as ditaduras militares. A raiz desses fenômenos é sistêmica e a alternativa tem de ser radical, isto é, antissistêmica. Em vários países da América Latina está colocada a discussão sobre uma alternativa anti-imperialista e anticapitalista: o socialismo do século XXI. Isto é um socialismo que supera os limites dos movimentos socialistas do século passado - o compromisso social-democrata com o sistema e a degeneração burocrática do chamado "socialismo real" - , mas recupera as bandeiras revolucionárias latino-americanas, de Simón Bolívar a Ernesto Che Guevara, de José Martí a Farabundo Martí, de Emiliano Zapata a Augusto César Sandino, de Zumbi dos Palmares a Chico Mendes. 
Siglas

UDC: Union Democratique du Centre

NSDAP: Partido Nazista (Nationalsozialistische Deutsche Arbeiterpartei)

FPÖ: Partido da Liberdade Austríaco

FN: Frente Nacional

Recebido em 26/6/2015 - Aprovado em 27/7/2015 